\title{
Application of Computer Aided Process Design in NC Machining
}

\author{
Liu Fuman Zhu Xiurong \\ Jilin Teacher's Institute of Engineering and Technology, \\ Changchun, Jilin, china 130052 \\ E-mai: zxr67811@163com
}

\begin{abstract}
Use of computer-aided process planning in $\mathrm{NC}$ machining of parts, not only can improve the overall level of manufacturing parts, can also greatly improve the level of product quality, computer-aided design technology designed to improve process efficiency, accelerate market response speed, shorten the technical preparations cycle. At the same time, promoting the standardization of technology to improve the process design level. Optimization of process design to promote technological progress, It will bring greater social and economic benefits
\end{abstract}

Keywords-CAPP; CNC Machine Tools; Programming Processing; Processing Technology; Applied Research

\section{INTRODUCTION}

Computer Aided Process Planning, also referred to as CAPP. Application of the theory of computer aided process design is code by using symbols, text and numbers that will be passed and parts-related information into a computer to form a professional component information database. At the same time, the thought process of personnel, experience the way a computer can recognize input to the control system, the formation process control library, computing logical analysis of parts and parameters, and generate the corresponding files. Its main role is to develop machining process by using a computer to complete the process of parts, and the parts drawings on blank processed into the required parts. When machining parts, machined parts various parameter name, quantity, material, size and shape of the input into the computer, the computer in a variety of information input, and can automatically generate process route machined parts and other documents ${ }^{[1]}$

CNC machining process, using computer-aided process design, can significantly reduce the processing time and improve the efficiency of CNC machining, CNC machining to improve information transfer and processing capabilities Therefore, in the CNC machining process, computer aided process design play an important role

\section{CNC MACHINING PROCESS}

\section{A. Analyze parts diagram, determine the installation reference}

Figure 1 shows the parts for the cylinder Disc-type parts, respectively 12 and 12 raised the recessed portion in the present procedure for the processing of 12 straight slots, since the drawings parts thinnest $1 \mathrm{~mm}$,so universal fixture jaw chuck and machine flat vices are unable to meet processing rigidity and precision so the use of special fixtures[2]
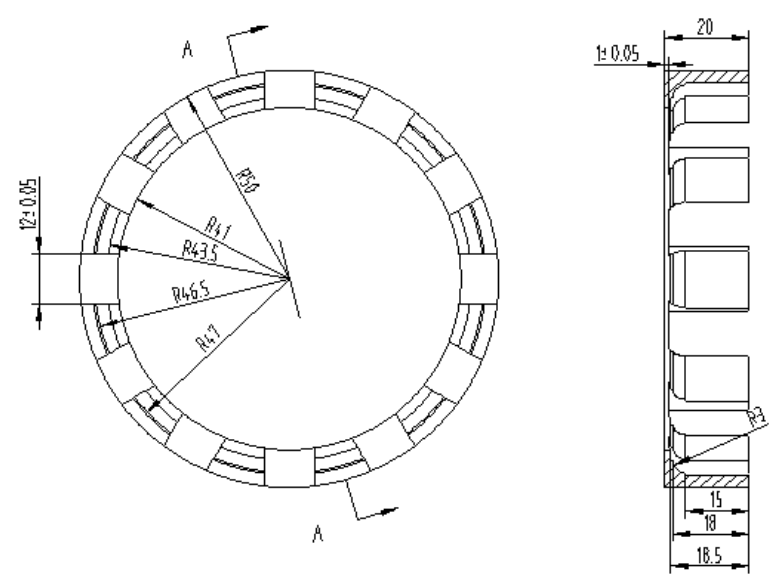

Figure 1. Machining Parts Drawing

B. Determining processing methods and processing line

Roughness straight groove parts is not required by the aviation standards requirements, so when milling can be invoked separately roughing, then finishing the program. Taking into account the selected parts of the blank is CNC lathe processed semi-finished products, its excellent cutting performance and surface without crust, so using climb milling when the milling method, which can improve the surface roughness and the processing of parts reduces tool wear. At the time of the straight groove processing, taking into account the accuracy of the machining of precision and positioning, can be used 10 mills, rough milling and fine milling, it is possible to meet the requirements of precision parts.[3]

In determining the route processing, the principle should follow the "base first, after the first hole surface, after the first coarse and fine" At the time of the straight groove contour machining, the use of blank is finished do not crusty 45\# steel, cutting good, so it should adopt Climb processing methods for processing, in order to improve the quality of its processing. At the same time, the tool cutting in and out, in order to avoid cutting tool and cut left into the source and retract the marks, using cycloid cutting mode.

Therefore, according to the characteristics of the blank, in the processing, select the bottom face as a positioning reference plane, the first in order of appearance of rough milled parts, 12 straight groove surface, in the case do not carry knives finishing, taking into account the need to make it rigid parts a special fixture to ensure the positioning accuracy of the work piece. Special fixture as shown: [4] 


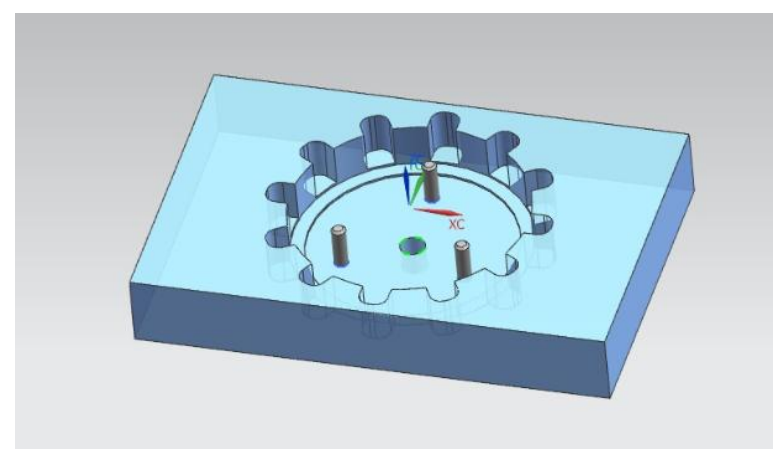

Figure 2. Clamp 1

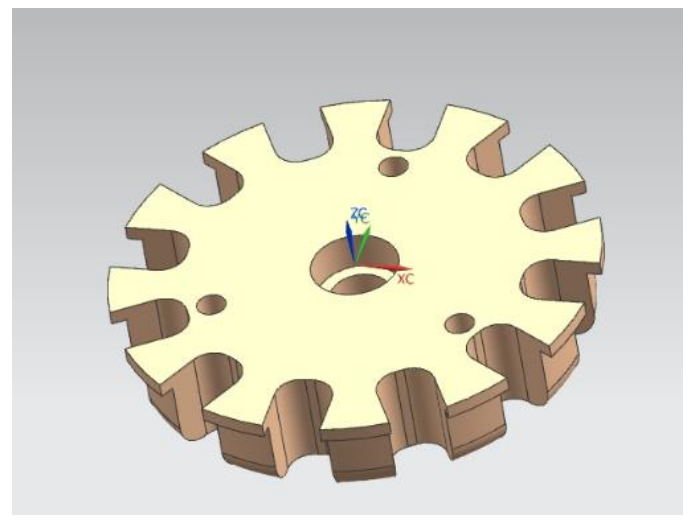

Figure 3. Clamp 2

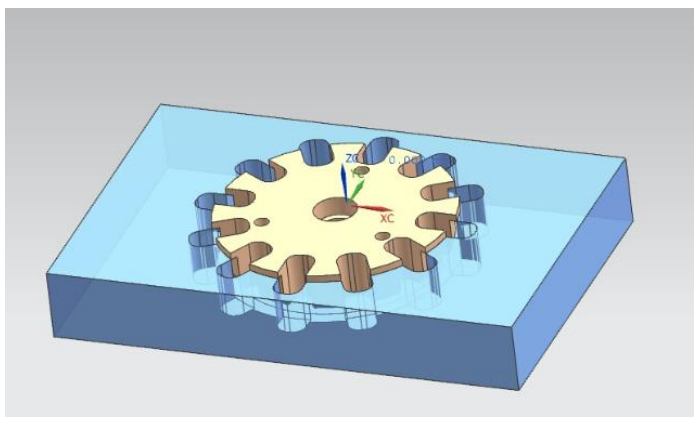

Figure 4. Clamp combination

\section{Select the cutting parameters}

Because parts of the blank is semi-finished products $45 \#$ steel, so the processing performance of its cutting, the use of machining used machines are $\mathrm{CNC}$ machining centers, taking into account the characteristics of the actual use of the vertical machining center performance and processing, and we use high-speed cycloid processing methods, its knife back to eat the amount of value is part of the final depth $19 \mathrm{~mm}$, but also due to the roughness of the surface of the machined parts is higher, so the need for rough machining, finishing, so the rough knife back to eat the amount, select the MID is $03 \mathrm{~mm}$,select finishing allowance is $02 \mathrm{~mm}$ Also, because the machine feed rate is $10000 \mathrm{~mm} / \mathrm{min}$, so in order to improve the efficiency of processing, roughing, contour selected direction feed amount (i.e. FFP1) to $1000 \mathrm{~mm} / \mathrm{min}$, the depth direction of the program do not participate in the design of cutting so feed (i.e. FFD) is the fastest machine, is $1000 \mathrm{~mm} / \mathrm{min}$ In finishing, in order to ensure the accuracy and contouring of surfaces, the feed rate of the selected contour direction (i.e. FFP1) of $200 \mathrm{~mm} / \mathrm{min}$.

Since the processing of parts and materials for the $45 \%$ of steel pieces, its good cutting performance, and the selected feed rate and the back of cut are relatively small, so by the look-up table reference, the cutting speed can get bigger, so choose the cutting speed of $1500 \mathrm{~m} / \mathrm{min}$. So when selecting parts 10 end mill for milling, its spindle speed: [5]

$$
n=\frac{1000 \times v}{\pi \times d}=2400 r / \mathrm{min}
$$

After calculation available, choose its roughing spindle speed 6000r / min, finishing spindle speed 6000r / min. Selection cutting three elements are shown in Table 1: [6]

TABle I Cutting ThreE ElEMENTS

\begin{tabular}{lcccc}
\hline & \multirow{2}{*}{$\begin{array}{c}\text { Spindle speed } \\
(\mathrm{r} / \mathrm{min})\end{array}$} & \multicolumn{2}{c}{ Feed rate $(\mathrm{mm} / \mathrm{min})$} & \multirow{2}{*}{$\begin{array}{c}\text { The back of } \\
\text { cut }(\mathrm{mm})\end{array}$} \\
\cline { 3 - 4 } Roughing & 2400 & FAL & FALD & 19 \\
Finishing & 2400 & 1000 & - & 19 \\
\hline
\end{tabular}

\section{Select the tool}

Because this part is so large production in order to reduce tool change time and auxiliary time so use carbide tools and grinding whole must bear coat, according to the parts diagram analysis tool selection D10 standard length blade cutter must be 4 to meet processing of rigid and timeliness.

\section{E. Simulation Processing}

According to the drawings analysis, processing line, choose the right tool for roughing and finishing. Before machining simulation process, repeated simulation processing, parameter optimization, define the machining program. [7][8]

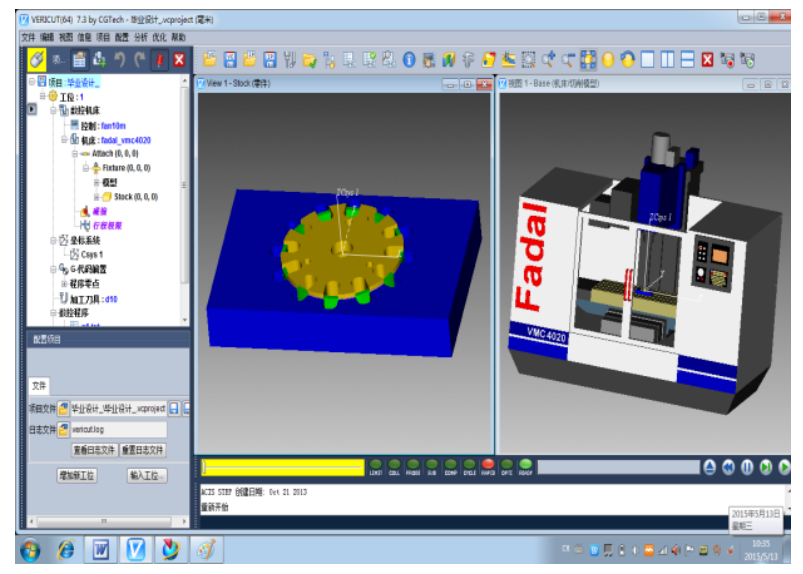

Figure 5. Parts Machining Simulation Figure

\section{COMPUTER-AIDED DESIGN APPLICATION IN CNC MACHINING}

CNC machining CAPP analysis provides information work platform. Technological knowledge database contains all the parts machining process parts related to the basis for the NC. Because the control can determine 
the kinds of information required for processing parts Thus, computer-aided process planning is the most important part of CNC machining a part, it can directly affect the quality of the product.



Figure 6. Parts processing final image

In addition, $\mathrm{CNC}$ machined parts, the process is to contact other parts processing products and an important link, but the traditional process does not apply to the modern parts processing requirements. After more than a variety of information to determine the parts processing, choose a processing method, right-click the processing method that can automatically generate the machining program, you can choose the process list. CAPP is an intermediate link between CAD and CAM, it is possible to generate technical documents.[9] CAPP technology will be used in CNC machining being can dramatically improve a company's design and manufacturing standards.

With CAD, CAPP, CAM cell technology has become more sophisticated, but also due to the proposed and developed CIMS and IMS, prompting CAPP to the intelligent, integrated and practical direction. CAPP in modern manufacturing, has important theoretical and practical needs of a wide range of pressing. CAPP system because the application can not only improve the efficiency of process planning and design quality, shorten cycle technical preparations for the majority of craft workers from the tedious, repetitive work of liberation provides a practical way, the process can be more investment technology test and process research, process design and can ensure the consistency, standardization, conducive to promoting the standardization process, More important is the process BOM data is to guide enterprise material purchasing, production planning and scheduling, organizing an important basis for production, resource balancing, cost accounting, etc., integration and lay a solid foundation for enterprise application CAPP system data information. Applications ERP system for process design:
Improve process design efficiency, accelerate market response speed, shorten the technical preparation cycle; Improve process design quality, reduce product costs Retreat; Help process engineers from tedious, repetitive low-level labor of liberation, there is more energy into technology test, process research, process design optimization, to promote technical progress; To promote the standardization of technology, improve the scientific process design, precision and standardization; Enterprise management information system provides real-time process data correctly, enterprise information infrastructure to improve source information.

\section{CONCLUSION}

Use of computer-aided process planning in NC machining of parts, not only can improve the overall level of manufacturing parts, can also greatly improve product quality level, so processing is product quality assurance.

In addition, computer-aided design technology designed to improve process efficiency, accelerate market response speed, and shorten the technical preparation cycle. [10]

To promote the standardization of construction processes, improve process design level. Optimization of process design to promote technological progress.

As long as the appropriate adjustments and modifications in accordance with specifications different tools and materials, to promote the use of CNC machining in various fields, will bring greater social and economic benefits.

\section{REFERENCES}

[1]Li Xianfeng from CAPP to MPM, digital manufacturing and management system Thinking and Practice [J] Manufacturing Technology \& Machine201109

[2]Li Xiangning,Liang Lichao Die CAPP System Research and Exploration [J] Mold industry 2007(5):15-18

[3]Ye Jiafei,Zeng Zhu CAPP in the mold NC machining [J] Mining machinery2011 (11): 127-129

[4]Luan Xiang Intelligent CAPP System Based Parts of engine cylinder head design and research $[\mathrm{J}]$ Mechanical design and manufacturing201104

[5]Yang Hongchun Research and development processes are characterized by a crankshaft to CAD / CAPP system [J] Modern Manufacturing Technology and Equipment201102 [6]Huang Juan,Wang $\mathrm{Li}$ 3D assembly CAPP technologies and products of [J] CAD / CAM and manufacturing information201109

[7]Yang Tiejiang BOM and PDM based CAPP system design and implementation [J] Modern Manufacturing Engineering201112

[8]Xiong Yingzhi CAPP system in the manufacturing information [J] Silicon Valley201204

[9]Zhou Xueliang,yuan Jingkui Harness CAPP system process database research [J] Automotive technology201105

[10]Hu Wei Self-development and application of ERP systems [J] Electrical Technology201104 